\title{
VALIDATION AND QUANTIFICATION OF THEOPHYLLINE AND SALBUTAMOL USING ION PAIR LIQUID CHROMATOGRAPHY
}

\author{
Shanti Laksmi Sophi, ${ }^{1,2}$, Sudibyo Martono ${ }^{1}$ and Abdul Rohman ${ }^{1,2 *}$
}

\author{
${ }^{1}$ Faculty of Pharmacy, Gadjah \\ Mada University, Yogyakarta, \\ 55281 Indonesia \\ ${ }^{2}$ Food and Drug Agency, \\ District of Yogyakarta, \\ Yogyakarta, Indonesia.
}

Submitted: $18-09-2016$

Revised: $10-10-2016$

Accepted: 11-11-2016

*Corresponding author Abdul Rohman

Email:

abdulkimfar@gmail.com

\begin{abstract}
Salbutamol and theophylline are administered in combination orally to provide the sinergistic effect of drugs. The aim of this study is to develop and to validate ion pair liquid chromatography to determine both drugs in pharmaceutical dosage form, especialy in syrup. Separation of drugs was performed with Spherisorb C-18 column (250x4.6mm; 10um). The mobile phase used was the mixture of acetic acid $1 \%$ : methanol $(60: 40 \mathrm{v} / \mathrm{v})$ which contain $3.5 \mathrm{mM}$ sodium-1octanesulphonate, as ion pairing reagent. The mobile phase was delivered isocratically with flow rate of $1 \mathrm{~mL} / \mathrm{min}$. UV detection was set at the wavelength of $277 \mathrm{~nm}$. The developed method was validated in terms of linearity, precision, accuracy, selectivity, and sensitivity. The precision of the method was evaluated using repeatability assay having relative standard deviation (RSD) values of $0.41-0.70 \%$ for theophylline and $0.08-0.24 \%$ for salbutamol. The recovery percentages were in the range of 98.28-101.02\% (theophylline) and 100.71-101.60\% for salbutamol. The developed method met the validation requirement for analysis of salbutamol and theophylline simultaneously in syrup dosage form. Furthermore, the method also provided acceptable result for syrup and tablet dosage forms containing Salbutamol and theophylline only, and tablet containing the combination of Salbutamol and theophylline.
\end{abstract}

Keywords: teophyllin, salbutamol, HPLC, sodium-1-octanesulphonate, validation

\section{INTRODUCTION}

The combination of theophylline, 1, 3dimethyl-7H-purine-2, 6-dione also known as dimethylxanthine as long-acting bronchodilator with Salbutamol, 4-[2-(tert-butylamino)-1hydroxyethyl - 2- (hydroxymethyl) phenol, as short acting $\beta$-agonist is drug of choice for treatment of chronic obstructive pulmonary disease. Salbutamol and theophylline (Figure 1) are administered in combination orally to provide the sinergistic effect of drugs (Anonymous 2005, Anonymous 2006, USP, 2009). The dosage form with this combination is reported to have better effect than a single drug.<smiles>Cn1c(=O)c2[nH]cnc2n(C)c1=O</smiles><smiles>CC(C)(C)NCC(O)c1ccc(O)c(CO)c1</smiles>

Figure 1. The chemical structures of salbutamol and theophylline.
Several methods have been reported for analysis of the individual of theophylline and salbutamol as well as their combination with other drugs in some dosage forms, namely ultraviolet spectrophotometry using multi-wavelength (Bhatia et al., 1998; Habib et al., 2005; Mishra et al., 2010), thin layer chromatography using silica gel $\mathrm{GF}_{254}$ (Mirfazaelian et al., 2002; Hiral et al., 2010), flow injection-spectrophotometric (Satinsky et al., 2002). However, most methods used for analysis of both drugs are high performance liquid chromatography along with its variation, either in pharmaceutical dosage form or in biomedical fluid.

Murthy dan Rani (2010) reported the analysis of transdermal dosage form containing both theophylline and salbutamol using reversed phase HPLC. Nagraju and Kaza (2009) reported HPLC for analysis of theophylline and salbutamol in bilayer sustained release. HPLC was also used for rapid analysis for the simultaneous quantification of theophylline and etophylline 
in human plasma (Nirogi et al., 2007). Ramakrishna et al. (2007) used a simple and rapid HPLC/UV method for the simultaneous quantification of theophylline and etophylline in human plasma. HPLC was also used for analysis of theophylline and salbutamol either individual or in combination in some dosage forms as reported by Basu and Pathak (1990), Marcia et al. (2002), Nikola et al. (2003), Ghulam et al. (2009), and Pai et al. (2009).

Most of reported methods for analysis of theophylline and salbutamol used reversed phase HPLC coupled with several detectors. Using literature review, there is yet any report for determination of theophylline and salbutamol in syrup continously using ion pair HPLC. There, the aim of present work is to develop a valid ion-pair HPLC method for theophylline and salbutamol in syrup.

\section{MATERIALS AND METHODS}

Theophylline (Jilin Shulan Pharm., China) and salbutamol sulphate (Neuland, India) were kindly obtained from PT. Dexa Medica, Indonesia. Methanol used as mobile phase was HPLC grade. Sodium-1-octanesulfonate HPLC was obtained from JT. Baker, Germany. Aquadest and aquabidest were purchased from PT. Ikapharmindo and Brataco Chemical (Indonesia). The instrument used is HPLC (Shimadzu, Japan) equipped with pump LC 20 AD Sil 20A and detector UV-Vis SPD 20 A. Reagents and solvents used were of proanalytical grade. The dosage form samples were taken from drug store in Yogyakarta.

\section{Chromatographic condition}

Separation of theophylline and salbutamol was carried out using column Spherisorb C-18 (25x4.6mm i.d; $10 \mu \mathrm{m})$. The mobile phase used was acetic acid 1\%: methanol $(60: 40 \mathrm{v} / \mathrm{v})$ containing sodium-1-octanesulfonate $3.5 \mathrm{mM}$ as ion pair reagent. The mobile phase was delivered isocratically with flow rate of $1 \mathrm{~mL} / \mathrm{min}$. UV detector was set at $277 \mathrm{~nm}$, and injection volume was $50 \mu \mathrm{L}$. All analysis was carried out in ambient temperature.

\section{Preparation of standard solution \\ Stock solution of theophylline \\ $(0.25 \mathrm{mg} / \mathrm{mL})$ and Salbutamol $(0.25 \mathrm{mg} / \mathrm{mL})$}

was prepared by dissolving $25 \mathrm{mg}$ theophylline and salbutamol separately in $100.0 \mathrm{~mL}$ acetic acid $1 \%$ : methanol $(60: 40 \mathrm{v} / \mathrm{v})$. The working standard solutions were prepared by diluting $2.0 \mathrm{~mL}$ stock solution of theophylline and $4.0 \mathrm{~mL}$ stock solution of salbutamol with acetic acid $1 \%$ : methanol $(60: 40 \mathrm{v} / \mathrm{v})$ upto $50.0 \mathrm{~mL}$ to obtain theophylline $10 \mu \mathrm{g} / \mathrm{mL}$ and salbutamol $20 \mu \mathrm{g} / \mathrm{mL}$, respectively.

\section{Sample preparation}

Sample of syrup equivalent to $25 \mathrm{mg}$ theophylline and $1 \mathrm{mg}$ salbutamol was dissolved in $100.0 \mathrm{~mL} 1 \%$ acetic acid: methanol $(60: 40 \mathrm{v} / \mathrm{v})$. A $2.0 \mathrm{~mL}$ of this solution was diluted in $50 \mathrm{~mL}$ volumetric flask and dissolved with $1 \%$ acetic acid: methanol $(60: 40 \mathrm{v} / \mathrm{v})$. The solution was filtered using $0.45 \mu \mathrm{m}$ filter and injected into HPLC system.

\section{Validation of analytical method}

The developed analytical method was validated by assessing several parameters according to International Conference on Harmonization (2002), namely selectivity, linearity, precision, accuracy and sensitivity. The selectivity test was performed by observing the chromatogram of theophylline, salbutamol, samples and spiked samples. The linearity evaluation of theophylline was performed at level concentrations of $1,5,10,15$ and $20 \mu \mathrm{g} / \mathrm{mL}$, and at level concentration of 10,15 , 20, 25 and $30 \mu \mathrm{g} / \mathrm{mL}$ for Salbutamol. Each concentration level was replicated 3 times. The precision study of theophylline and salbutamol was performed at level concentrations of 8,10 and $12 \mu \mathrm{g} / \mathrm{mL}$, and at level of 16,20 and $24 \mu \mathrm{g} / \mathrm{mL}$, respectively. Each level concentration was done in 6 replicates. Accuracy was performed by addition of known amount of theophylline and salbutamol standards to a known concentration of sample solution. The level concentration of theophylline for accuracy studies is at $1,5,10$, 15 , and 20ppm, and at levels of 10, 15, 20, 25 and $30 \mathrm{ppm}$ for salbutamol. Each level is subjected to 3 times replication. Sensitivity was evaluated by determining limit of detection and limit of quantitation, as determined by calculation based on linearity regresion (Miller and Miller, 2005). 


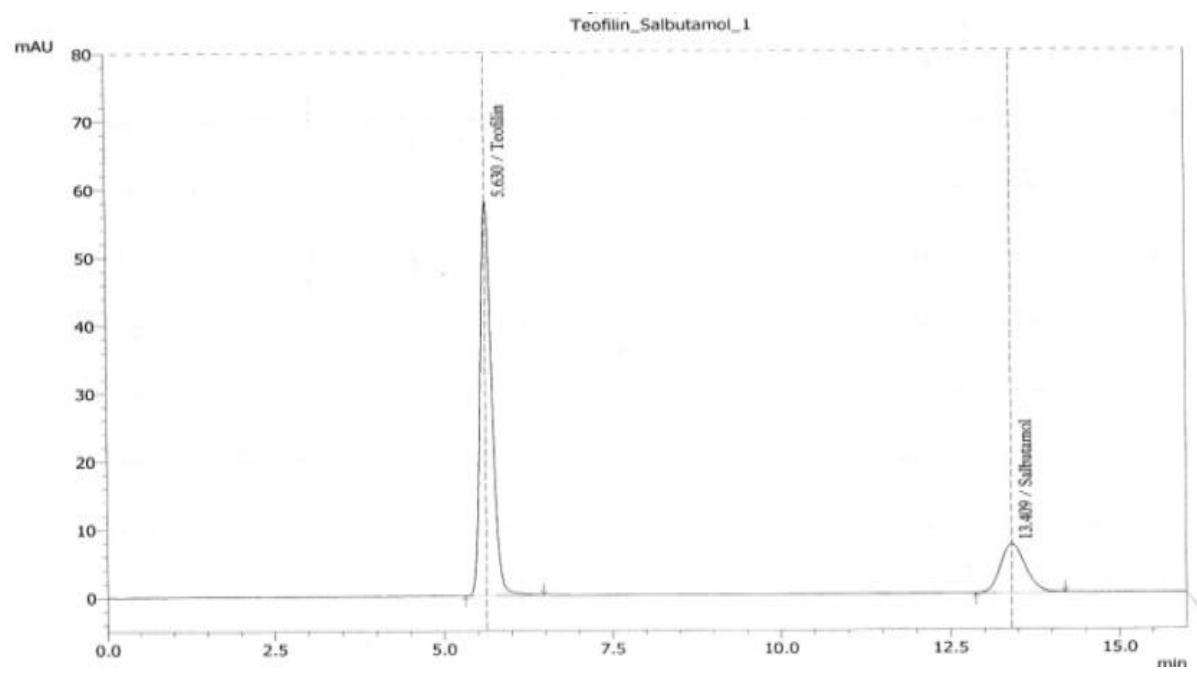

Figure 2. Chromatogram of theophylline $10 \mathrm{ppm}$ and Salbutamol $20 \mathrm{ppm}$ using the optimized condition.

\section{RESULT AND DISCUSSION}

Theophylline and salbutamol have $\mathrm{N}$ with nonbonding electron that contibute to the basic characteristic of drugs. The addition of acetic acid in the mobile phase will maximize the protonation process of both drugs. As a consequence, the protonated N-basic on theophylline and salbutamol will produce more polar property. Hydrophobic side from sodium-1-octanesulfonate as ion pairing reagent will interact with stationary phase of $\mathrm{C}$ 18, while the hydrophyllic side $\left(\mathrm{SO}_{3}^{-}\right)$can interact with the protonated N-basic on theophylline and salbutamol, and therefore, both drugs can be separated with acceptable resolution using the optimized HPLC condition.

The selectivity test showed that HPLC condition used had good separation, as indicated by resolution value (Rs) of $>2.0$ (Figure 2). The resolution of salbutamol to theophylline is around 15.55, while that of salbutamol to the closest peak is 2.61. Linearity studies revealed that the values of coefficient of correlation ( $r$ ) for the relationship between concentration of drugs $(x$-axis) and peak area (y-axis) are $>0.99999$ over concentration range of $1-20 \mu \mathrm{g} / \mathrm{mL}$ for theophylline and $1-30 \mu \mathrm{g} / \mathrm{mL}$ for salbutamol (Figure 3). Furthermore, the \% $\mathrm{y}$-intercept obtained is $0.03 \%$ and $0.33 \%$ for theophylline and salbutamol, respectively, indicating low systematic error and could be negligible (A huja and Dong, 2005; Snyder et al., 2010). From the values of $r$ and $\% y$-intercept, it could be concluded that the developed method were linear over the concentration ranges used.

The precision was determined by assessing the repeatability test of analytical method. Precision is usually measured as relative standard deviation (RSD) of a set of data. In this study, three levels, i.e. $80 \%, 100 \%$ and $120 \%$ from target value, corresponding to 8, 10 and $12 \mathrm{ppm}$ (theophylline) and 16, 20 and $24 \mathrm{ppm}$, were used. The RSD values obtained were $0.70 \%, 0.41 \%$, and $0.42 \%$ (theophylline), and $0.21 \%, 0.09 \%$, and $0.24 \%$ for salbutamol. According to Horwitz function, the maximum RSD value acceptable for the analyte level of $1 \mathrm{ppm}$ is $16 \%$. AOAC set the maximum acceptable RSD value at $11 \%$ for the same analyte level (Gonzalez and Herrador 2007). Therefore, it could be stated that the HPLC method showed good precision for analysis of theophylline and salbutamol based on RSD values obtained.

The accuracy of analytical method was determined using standard addition methods in which samples were added with standard solution of drugs in known amount in three different levels. The recovery values of drugs were assessed. The recovery value obtained for theophylline is $98.78-101.94 \%$, while that of salbutamol is $100.66-101.65 \%$. 

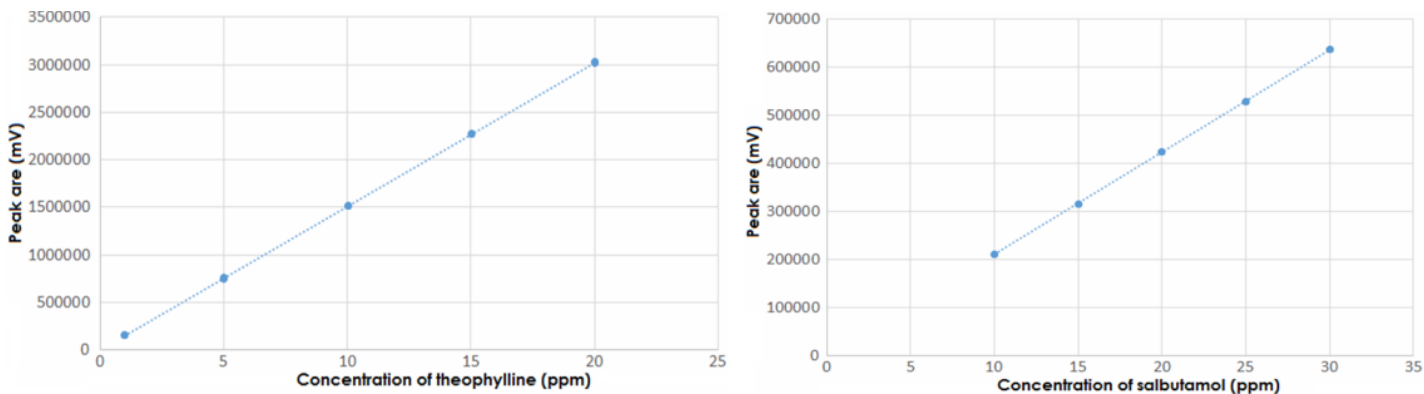

Figure 3. The calibration curve expressing the relationship between concentration of drugs ( $\mathrm{x}$-axis) and peak area (y-axis).

Table I Assay of theophylline and salbutamol for several pharmaceutical dosage form.

\begin{tabular}{ccc}
\hline \multirow{2}{*}{ Dosage form } & \multicolumn{2}{c}{ Concentration of drugs } \\
\cline { 2 - 3 } & Theophyllin & Salbutamol \\
\hline SR-TS & $49.56 \pm 0.08 \mathrm{mg} / 5 \mathrm{~mL}$ & $0.52 \pm 0.0003 \mathrm{mg} / 5 \mathrm{~mL}$ \\
SR-TT & $153.42 \pm 0.22 \mathrm{mg} / 15 \mathrm{~mL}$ & - \\
SR-ST & - & $1.97 \pm 0.0011 \mathrm{mg} / 5 \mathrm{~mL}$ \\
TB-TS & $127.58 \pm 0.22 \mathrm{mg} / \mathrm{tablet}$ & $0.96 \pm 0.0021 \mathrm{mg} / \mathrm{tablet}$ \\
TB-TT & $146.78 \pm 0.39 \mathrm{mg} /$ tablet & - \\
TB-ST & - & $3.98 \pm 0.0364$ \\
\hline
\end{tabular}

Syrup contains theophylline-salbutamol (SR-TS); Syrup contains theopbylline (SR-TT); Syrup contains salbutamol (SR-ST); Tablet contains theophylline-salbutamol (TB-TS); tablet contains theophylline (TB-TT); tablet contains salbutamol (TB-ST).

According to AOAC as cited from Gonzalez and Herrador (2007), the acceptable recovery percentage range is $80-110 \%$ for the analyte level of $1 \mu \mathrm{g} / \mathrm{mL}$. Therefore, the developed method was accurate for quantification of theophylline and salbutamol in pharmaceutical dosage form.

The sensitivity of instruments used for analysis of theophylline and salbutamol was expressed as limit of detection (LOD) and limit of quantification (LOQ). The values of LOD and LOQ were determined based on linear regression as in Miller and Miller (2005). The LOD values for theophylline and salbutamol are $0.066 \mathrm{ppm}$ and $0.295 \mathrm{ppm}$, respectively; while, LOQ values are $0.219 \mathrm{ppm}$ and 0.991 ppm, respectively for theophylline and salbutamol. The developed method was subsequently used for assay of several pharmaceutical dosage forms that contains only theophylline or salbutamol as well as those contain both drugs (Table I). The results showed that the evaluated syrup and tablet contained theophylline and salbutamol in the range as labelled.

\section{CONCLUSION}

Ion pair HPLC has been validated by determining several parameters including selectivity, linearity, precision, accuracy and sensitivity. The validation data obtained are acceptable. The developed method is successfully used for analysis of theophylline and salbutamol for syrup and tablet dosage forms which contain only theophylline or only salbutamol, as well as tablet containing the combination of theophylline and salbutamol.

\section{ACKNOWLEDGEMENT}

The first author thank to National Food and Drug Agency, District of Yogyakarta for instrument facilities during this study.

\section{REFE RE NCES}

Ahuja S., Dong MW. 2005. Handbook of Pharmacentical Analysis by HPLC. Volume 6. New York, Elsevier Academic Press. p. 35.

Anonymous (2005). The Merck Index, 14th Ed., Merck Research Laboratories, Merck 
\& Co, Inc, White house station, NJ, USA.

Anonymous (2005). The Pharmacopoeia of The Peoples Republic of China, People's Medical Publishing House, 2005.

Basu M., Pathak B. 1990. Estimation of salbutamol sulphate in pharmaceutical formulations. Indian Drugs, 28, 109-110.

Bhatia NM., Jain DK., Trivedi P. 1998. Simultaneous analysis of salbutamol sulfate and bromhexine hydrochloride from solid dosage form using multi wave length UV-spectrophotometry. Indian Drugs, 35, 566-569.

Ghulam M., Mahmood A., Muhammad AM., \& Muhammad WA. 2009. A new reverse phase HPLC method with fluorescent detection for the determination of salbutamol sulfate in human plasma. Bulletin of Chemical Society of Ethiopia,. 23, 1-8.

Gonzalez AG., Herrador MA. 2007. A Practical Guide to Analytical Method Validation, Including Measurement Uncertainty and Accuracy Profiles. Trends in Analytical Chemistry, 26 (3), 227-238.

Habib IHI., Hassouna MEM., Zaki GA. 2005. Simultaneous spectrophotometric determination of salbutamol and bromhexin in tablets. Farmaco. 60: 249-254.

Hiral DN., Rajeesree MC., Alpesh PK. 2010. Thin Layer Chromatographic Methode for the Determination of Ternary Mixture Containing Salbutamol Sulphat, Ambroxol Hydrochloride and Theophylline. Int J Pharm Scie, 2(1), 390-394.

International Conference on Harmonization, (2002). Guidance on analytical method validation, International convention on quality for the pharmaceutical industry. Toronto, Canada.

Kazakevich YV., LoBrutto R. 2007. HPLC for Pharmacentical Scientist, John Wiley \& Sons p. 471-481.

Marcia SB., Marcia CV., Heloisa P., Rodolfo O., Jose NR. 2002. Simultaneous determination of caffeine, theo- bromine, and theophylline by high performance liquid chromato-graphy. J Chrom Scie, 40, 45-48.

Miller JN., Miller JC. 2005. Statistics and Chemometrics for Analytical Chemistry. $5^{\text {th }}$ Edition, Pearson Education Ltd., Edinburgh, UK.

Mirfazaelian A., Goudarzi M., Tabatabaiefar M., Mahmoudian M. 2002. A Quantitative Thin Layer Chromatography Method for Determination of Theophylline in Plasma.JPharPharm Scie, 5(2), 131-134.

Mishra AK., Kumar M., Mishra A., Verma A., Chattopadhyay P. 2010. Validated UV Spectroscopic Method for Estimation of Salbutamol from Tablet Formulation. Scholars Research Library, 2(3), 207-211.

Murthy NS., Hiremath SR. 2001. Formulation and Evaluation of Controlled release transdermal Patches of Theophylline - Salbutamol Sulphate. J Asthma, Allergy Immunology, 2(1), 1-9.

Nagraju R., Kaza R. 2009. Formulation and evaluation of bilayer sustained released tablets of salbutamol and theophylline. Int $J$ Pharm Scie Nanotechnology, 2(3), 638-646.

Nikola L., Dragica Z., Olgica SS., Igor K. 2003. Development and validation of the HPLC method for the determination of theophylline serum concentration. Bulletin Chemistry and Tecbnology Macedonia, 22, 97-104.

Nirogi RV., Kandikere VN., Shukla M., Mudigonda K., Ajjala DR. 2007. A simple and rapid HPLC/UV method for the simultaneous quantification of theophylline and etofylline in human plasma. J Chrom B, 848, 271-276.

Pai PNS., Rao GK., Murthy MS., Agarwal A., Puranik S. 2009. Simultaneous determination of salbutamol sulphate and bromhexine hydrochloride in tablets by reverse phase liquid chromatography. Ind J Pharm Scie, 71, 53-55.

Ramakrishna VSN., Vishwottam NK., Manoj S., Koteshwara M., Devender RA. 2007. A simple and rapid HPLC/ UV method for the simultaneous 
quantification of theophylline and etofylline in human plasma. $J$ Chrom B, 848, 271-276.

Satinsky D., Karlicek R., Svaboda A. (2002). Using on-line solid phase extraction for flow injection spectrophotometric determination of salbutamol. Analytica Chimica Acta,. 455, 103-109.
Snyder LR., Kirkland JJ., Dolan JW. 2010. Introduction to Modern Liquid Chromatography. Third Edition. John Wiley \& Sons Inc. Publication, New York, USA.

The United State Phamacopoeia (2009). United State Pharmacopoieal Convention, $32^{\text {th }}$ Ed., Rockvilie, USA. 